\title{
A COMPARATIVE STUDY OF EFFICACY OF HAND FOOT PSORALEN-ULTRAVIOLET A THERAPY VERSUS SEQUENTIAL THERAPY OF TOPICAL CLOBETASOL PROPIONATE WITH TOPICAL CALCIPOTRIOL OINTMENT IN PALMOPLANTAR PSORIASIS
}

\author{
Abirami Punniyaseelan', Revathy Mathan² \\ ${ }^{1}$ Assistant Professor, Department of Dermatology, Government Sivagangai Medical College. \\ ${ }^{2}$ Associate Professor, Department of Sexually Transmitted Diseases, Government Coimbatore Medical College.
}

ABSTRACT
BACKGROUND
Palmoplantar psoriasis that accounts for $3 \%-4 \%$ of all psoriasis cases produces significant functional and social disability.
Reduction of pain and improvement in the function of limbs are more important therapeutic goals than complete clearance. This
prospective, randomised, controlled study was conducted in Coimbatore Medical College, a tertiary care centre in Tamilnadu.
We conducted the study on 50 patients from September 2011 to November 2012 .
Aims and Objectives- The aims and objectives of the study was to compare the efficacy, to observe the reduction in percentage of
psoriasis area and severity index score (PASI SCORE) above 50\% and to observe the adverse effects in first 6 months and duration
of remission in the next 6 months.

\section{MATERIALS AND METHODS}

We divided all patients into two groups- Who had taken phototherapy was Group A and Who had taken sequential therapy was Group B. SPSS (Statistical Package for Social Sciences) Ver. 20 was used to perform statistical analysis. T-test for equality of means was conducted to compare the two groups.

\section{RESULTS}

In Group A 81.8\% of the patients and in Group B 91.6\% of the patients showed more than 50\% reduction of PASI score. The initial PASI score and percentage reduction was compared with $8^{\text {th }}$ week score, $16^{\text {th }}$ week and $24^{\text {th }}$ week of treatment of both groups. The ' $\mathrm{t}$ ' test result of percentage reduction showed significant difference at the end of $8^{\text {th }}$ week (' $\mathrm{t}$ ' value $2.618, \mathrm{P}<0.01$ ), 16 ${ }^{\text {th }}$ week (' $\mathrm{t}$ ' value $=3.288, \mathrm{P}<0.05)$, and $24^{\text {th }}$ week (' $\mathrm{t}$ ' value $\left.=3.324, \mathrm{P}<0.05\right)$.

\section{CONCLUSION}

Efficacy of sequential manner is better than topical PUVA. Patients on PUVA therapy group developed more adverse effects and the duration of remission maintenance was short.

\section{KEYWORDS}

Palmoplantar Psoriasis, PASI Score, PUVA, Sequential Therapy, Calcipotriol Ointment.

HOW TO CITE THIS ARTICLE: Punniyaseelan A, Mathan R. A comparative study of efficacy of hand foot psoralen-ultraviolet A therapy versus sequential therapy of topical clobetasol propionate with topical calcipotriol ointment in palmoplantar psoriasis. J. Evolution Med. Dent. Sci. 2017;6(45):3528-3533, DOI: 10.14260/Jemds/2017/761

\section{BACKGROUND \\ Palmoplantar psoriasis produces significant functional and social disability.[1] Psoriasis Area Severity Index score was first described in 1978. The severity of psoriasis is assessed by PASI score. According to Carlin et al, PASI score reduction of $50 \%$ corresponds to a clinically significant endpoint in assessment of palmoplantar psoriasis.[2-5]}

\section{Clinical Variants of Palmoplantar Psoriasis according to Nobel Classification[6]}

1. Sharply demarcated erythematous patches and covered by adherent psoriatic scales.

Financial or Other, Competing Interest: None.

Submission 28-04-2017, Peer Review 24-05-2017,

Acceptance 30-05-2017, Published 05-06-2017.

Corresponding Author:

Dr. Abirami Punniyaseelan,

No. 175A/15A, New Colony,

Thuraimangalam (Near Head Post Office),

Perambalur District-621220,

Tamilnadu.

E-mail: drabiderm@gmail.com

DOI: $10.14260 /$ jemds $/ 2017 / 761$

\section{(c) $($ ) $\$$}

2. Diffuse mild hyperkeratosis with scales.

3. Very thick hyperkeratotic layer resembling hereditary type of palmoplantar keratoderma.

4. Diffuse erythema.

\section{Multi-Modality Therapeutic Strategies}

Topically, treatment may be given in different ways like combination therapy, rotational therapy[7] and sequential therapy. ${ }^{[8]}$ Our study was based on sequential therapy. It has three steps. They are clearing or quick phase, transitional phase and maintenance phase.

Topical Calcipotriol and Clobetasol Propionate Ointment The effect of calcipotriol ointment is slower than topical corticosteroid. For rapid activity, calcipotriol is combined with steroid. Calcipotriol is a synthetic vitamin D derivative, which acts by binding to vitamin D receptor.

\section{PUVA Therapy}

FDA gave approval for PUVA therapy in 1982. The mechanism of action has three steps. ${ }^{[9,10]}$ Psoralen binds with DNA double strand before irradiation. After UVA exposure bind with pyrimidine base to form cyclobutane monoadducts 
(MA). After absorbing a second photon, psoralen-DNA crosslink is formed by $4 \mathrm{MA}$. The reactive oxygen species are formed by this crosslink; it damages cell membrane and inhibits DNA replication which causes cell cycle arrest. So, there is alteration of cytokine and cytokine receptor, which causes apoptosis of lymphocytes and keratinocytes.

\section{Soak PUVA}

To avoid the side effects of systemic PUVA, topical PUVA is useful. Hand and/or foot soak in 8 Methoxypsoralen $2.5 \mathrm{mg} / \mathrm{L}$ for 15 minutes followed by UVA irradiation weekly two or three times is effective; $1 \mathrm{~mL}$ contains $5 \mathrm{mg}$ of $8 \mathrm{MOP}$.[11] In the literature, there is no specific data regarding the initial dose of UVA irradiation for palmoplantar psoriasis. It depends upon the severity of the disease and higher UVA doses are recommended to treat the thicker skin of palmoplantar psoriasis.

Moisturisation is needed before phototherapy in elderly populations, because phototherapy itself can aggravate xerosis and pruritus.[12] The emollients will decrease the total UVA dose required to clear psoriasis.[13,14]

PUVA therapy has three phases. They are clearing, maintenance and tapering phase. In clearing phase, radiation is given up to $90 \%$ clearance of lesions. In maintenance phase, the irradiation is maintained until clearance of remaining lesions. Then taper the radiation dose weekly once, two weeks once, three weeks once, four weeks once and then stop the treatment.

\section{MATERIALS AND METHODS}

We conducted prospective, randomised, controlled study by convenient sampling method. We took 50 patients as sample size who attended Outpatient Department of Dermatology in Coimbatore Medical College Hospital from September 2011 to November 2012. The treatment duration was six months and the followup period was six months. The results were tabulated and appropriate tests of significance were worked up. SPSS (Statistical Package for Social Sciences) Ver. 20 was used to perform statistical analysis. T-test for equality of means was conducted to compare the two groups.

\section{Inclusion Criteria}

Patients aged between 18 - 60 years with written consent and who had not used other forms of topical treatment during the previous four weeks.

\section{Exclusion Criteria}

Age less than 18 years and who had not given consent. Pregnant and lactating women were also excluded.

Patients were evaluated with complete history, dermatological and systemic examination. Biopsy was also done in doubtful cases.

\section{Treatment Protocol}

The 50 patients were randomly arranged and by using computer generated random table. They were divided into Group A and Group B and each constituted of 25 patients.

\section{Group A}

25 patients were included in this group; $0.5 \mathrm{~mL}$ of $1 \% 8$ Methoxypsoralen lotion was diluted in two litres of water. Hands and feet were soaked in that solution for 15 minutes.
Then patient was advised to mop both palms and soles and to apply emollients followed by UVA exposure, 30 minutes after soak. Initial dose of UVA is $1 \mathrm{~J} / \mathrm{cm}^{2}$ with increment dose of 0.5 $\mathrm{J} / \mathrm{cm}^{2}$ on every visit with a frequency of two times per week for six months. Eyes were protected by using goggles during treatment.

\section{Group B}

25 patients were included in this group. Sequential therapy of $0.05 \%$ Clobetasol propionate ointment with $0.005 \%$ Calcipotriol ointment was given for six months.

\section{Phase 1}

Combination of clobetasol propionate and calcipotriol ointment once a day application in the first month.

\section{Phase 2}

Clobetasol propionate for weekends and calcipotriol for week days once a day application in the second and third month.

\section{Phase 3}

Calcipotriol ointment once a day application in the fourth, fifth and sixth month.

\section{Treatment Assessment}

Severity and extent of disease were calculated by using "Psoriasis Area Severity Index Score" (PASI Score) and PASI percentage reduction score. PASI score was calculated before treatment at the end of $8^{\text {th }}$ week, $16^{\text {th }}$ week and $24^{\text {th }}$ week. PASI score for Palmoplantar psoriasis.

PASI $=0.2(\mathrm{EU}+\mathrm{IU}+\mathrm{DU}) \mathrm{AU}+0.4(\mathrm{EL}+\mathrm{IL}+\mathrm{DL}) \mathrm{AL}$

Area of Psoriatic involvement for Palms and Soles were calculated as 1 . It means $10 \%$ of area was involved. Severity of Erythema, Induration, Desquamation was calculated as follows" 0- None, 1- Slight, 2- Moderate, 3- Severe, 4- Very Severe.

\section{RESULTS}

Out of 25 patients selected for Group A and Group B, 22 patients came for treatment till twenty four weeks in Group A, 24 patients came for treatment till twenty four weeks in Group B. Only those patients were included for analysis.

\begin{tabular}{|c|c|c|c|}
\hline $\begin{array}{r}\text { Sl. } \\
\text { No. }\end{array}$ & $\begin{array}{c}\text { PASI Percentage (\%) Reduction } \\
\text { at the End of Treatment }\end{array}$ & Group A & Group B \\
\hline 1 & $10-20$ & - & - \\
\hline 2 & $21-30$ & - & - \\
\hline 3 & $31-40$ & - & - \\
\hline 4 & $41-50$ & 4 & 2 \\
\hline 5 & $51-60$ & 8 & 2 \\
\hline 6 & $61-70$ & 7 & 4 \\
\hline 7 & $71-80$ & 3 & 11 \\
\hline 8 & $81-90$ & - & 5 \\
\hline \multicolumn{3}{|c|}{ Table 1. PASI Percentage Reduction at the End of } \\
Treatment \\
\hline
\end{tabular}

\section{PASI Reduction Score and Percentage Reduction}

The mean PASI score before treatment for Group A and Group B were 3.4 and 3.1 respectively. The ' $t$ ' test results did not show any significant difference in the average initial score between Group A and Group B, ( $\mathrm{t}$ value= 0.753, P > 0.05). 
After 8 weeks of treatment, the mean PASI score for both groups were 2.7 and 2.2 respectively ( $\mathrm{t}$ value $=10.035 \mathrm{P}<$ 0.01 and $t=8.571 \mathrm{P}<0.01$ ). After 16 weeks of treatment, the mean PASI score for both groups were 2.1 and 1.5 respectively ( $\mathrm{t}$ value $=12.889 \mathrm{P}<0.01$ and $\mathrm{t}=9.603 \mathrm{P}<0.01$ ). After 24 weeks of treatment, the mean PASI score for both groups were 1.4 and 0.9 respectively ( $\mathrm{t}$ value $=13.754 \mathrm{p}<$ 0.01 and $t=9.843 \mathrm{P}<0.01$ ). T test conducted for Group A and Group B comparing initial scores with scores at $8^{\text {th }}, 16^{\text {th }}$ and $24^{\text {th }}$ week showed significant reduction in the scores at all three periods.

After 8 weeks of treatment, the mean PASI percentage reduction for both groups were $21.28 \%$ and $29.55 \%$ respectively. After 16 weeks of treatment, the mean PASI percentage reduction for both groups were $40.06 \%$ and $50.56 \%$ respectively. After 24 weeks of treatment, the mean PASI percentage reduction for both groups were $60.50 \%$ and $70.77 \%$ respectively.

\begin{tabular}{|c|c|c|c|c|c|}
\hline & & Mean & S.D & T Value & P Value \\
\hline \multirow{2}{*}{$\begin{array}{l}\text { After (8 } \\
\text { Weeks) }\end{array}$} & $\mathrm{A}$ & 21.28 & 9.30 & \multirow{2}{*}{2.618} & \multirow{2}{*}{$\mathrm{P}<0.01$} \\
\hline & B & 29.55 & 11.83 & & \\
\hline \multirow{2}{*}{$\begin{array}{c}\text { After (16 } \\
\text { Weeks) }\end{array}$} & $\mathrm{A}$ & 40.06 & 10.90 & \multirow{2}{*}{3.288} & \multirow{2}{*}{$\mathrm{P}<0.05$} \\
\hline & $\mathrm{B}$ & 50.56 & 10.74 & & \\
\hline \multirow{2}{*}{$\begin{array}{l}\text { After (24 } \\
\text { Weeks) }\end{array}$} & A & 60.50 & 10.26 & \multirow{2}{*}{3.324} & \multirow{2}{*}{$\mathrm{P}<0.05$} \\
\hline & $B$ & 70.77 & 10.66 & & \\
\hline
\end{tabular}

Table 2. Statistics Table for PASI Percentage Reduction

According to ' $\mathrm{t}$ ' test on the basis of more than $50 \%$ reduction in PASI score, the $\mathrm{p}$ value showed $<0.01$ and $<0.05$ after $8^{\text {th }}, 16^{\text {th }}$ and $24^{\text {th }}$ weeks of treatment. As the ' $\mathrm{p}^{\text {' value }}$ was significant, this difference in the treatment regimen was not merely by chance. Sequential therapy regimen had a definitive role in treatment of palmoplantar psoriasis than PUVA therapy.

In Group A, out of 22 patients 18 (81.8\%) showed more than $50 \%$ reduction of PASI. None of the patients showed complete clearance of both palmar and plantar psoriasis. Four patients showed complete clearance of lesion in the palms. Two patients showed complete clearance of lesion in the soles. The average period of clearance of lesions was at 19 weeks. In six months followup period, 3 patients showed relapse after 15 weeks of average period of remission.

In Group B out of 24 patients, 22 (91.6\%) showed more than $50 \%$ reduction of PASI score. Here also none of the patients showed complete clearance of both palmar and plantar psoriasis. Seven patients showed complete clearance of lesion in the palms and five patients showed complete clearance of lesion in the soles. The average period of clearance of lesions was at 20.3 weeks. In six months followup period, 2 patients showed relapse after 20 weeks of average period of remission.

\section{Adverse Effects \\ Group A}

4 patients (18.18\%) developed adverse effects during treatment. Two patients developed erythema over palms and soles, two patients developed burning sensation.

\section{Group B}

3 patients (12.5\%) developed adverse effects during treatment. One patient developed erythema over soles and two patients developed itching and burning sensation over soles.

\begin{tabular}{|c|c|}
\hline Group & Adverse Effect \\
\hline A & 4 Patients (18.18\%) \\
\hline B & 3 Patients (12.5\%) \\
\hline \multicolumn{2}{|c|}{ Table 3. Adverse Effects } \\
\hline
\end{tabular}

Image 1.

PUVA Therapy

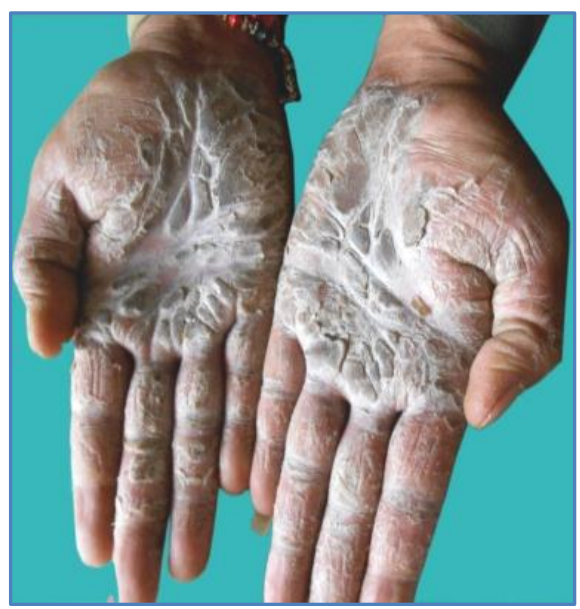

Before Treatment

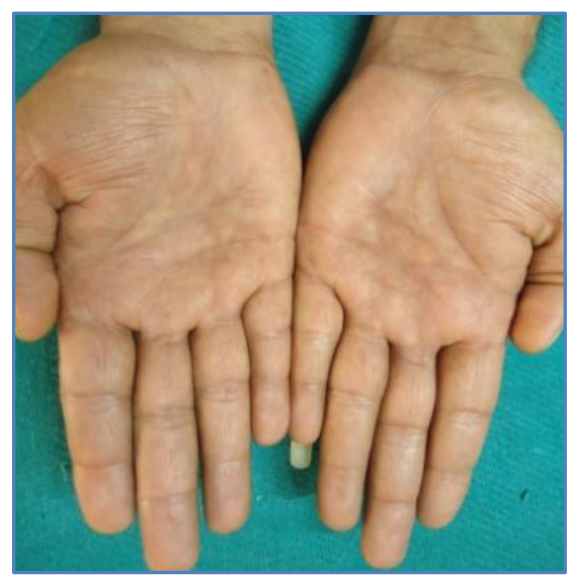

20 Weeks After Treatment

Image 2. Calcipotriol Combinations

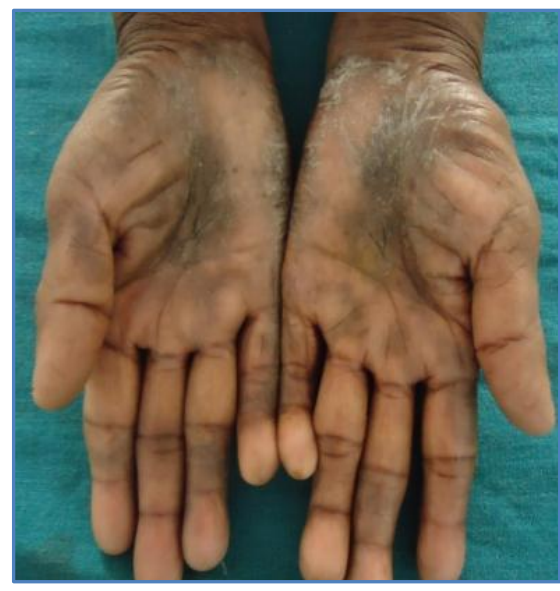

Before Treatment 


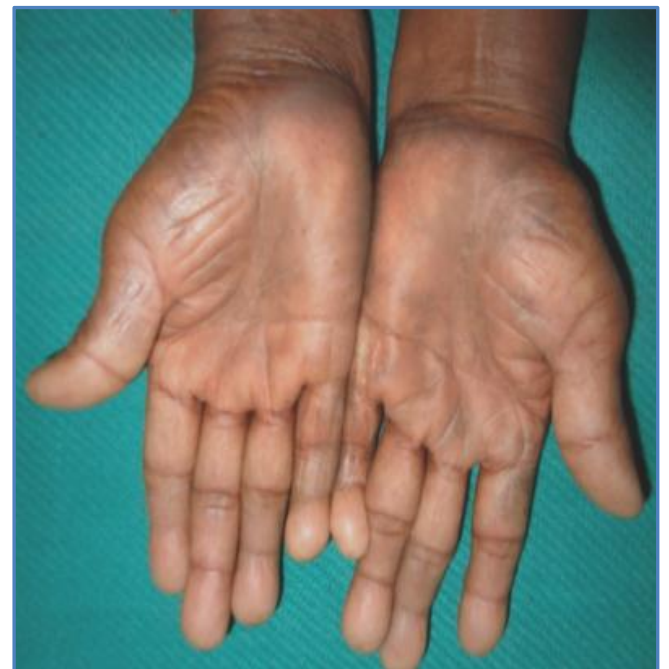

17 Weeks After Treatment

Image 3. Side Effect

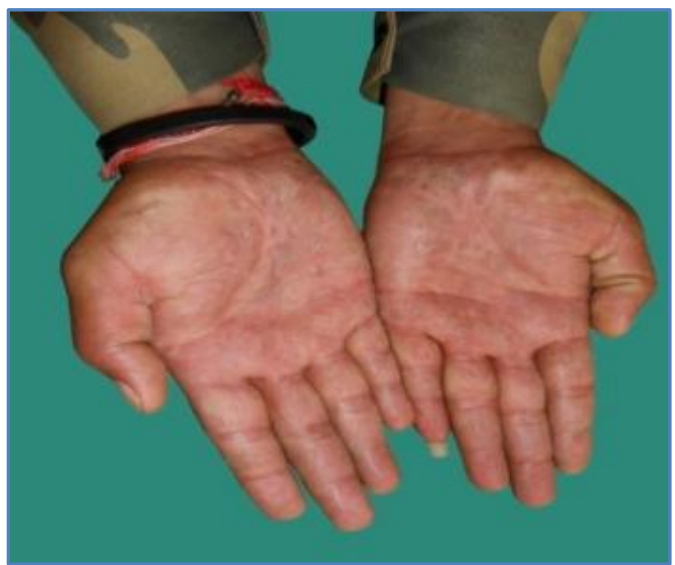

Diffuse Erythema due to PUVA Therapy

\section{DISCUSSION}

In our study on the treatment of palmoplantar psoriasis with topical PUVA therapy and sequential treatment with topical calcipotriol and clobetasol ointment, the mean age of the patients presented with palmoplantar psoriasis was 43.32 years; $68 \%$ of patients were males and $32 \%$ were females and the mean duration of the disease was 17 months. Response to treatment were assessed based on reduction in PASI score and its percentage at $8^{\text {th }}, 16^{\text {th }}$ and $24^{\text {th }}$ week.

\section{Topical PUVA (Group A)}

The starting dose of UVA therapy was $1 \mathrm{~J} / \mathrm{cm}^{2}$ with an increment of $0.5 \mathrm{~J} / \mathrm{cm}^{2}$ on subsequent visit. The maximum dose reached was $24.5 \mathrm{~J} / \mathrm{cm} 2$ for some patients. In our study, the Group A patients were treated with 8-methoxypsoralen solution along with ultraviolet A therapy twice weekly showed reduction in PASI score of $21.28 \%, 40.06 \%, 60.50 \%$ at the end of $8^{\text {th }}, 16^{\text {th }}$ and $24^{\text {th }}$ week respectively. Maximum improvement was observed at $24^{\text {th }}$ week.

There are many studies in literature about the topical PUVA in the treatment of palmoplantar psoriasis, but the results were not consistent. Various studies conducted for the treatment of palmoplantar psoriasis are-
1. Wilkinson JD, Ralfs IG et al, in this study $67 \%$ of patients showed considerable improvement with topical application of methoxypsoralen along with UVA.[15]

2. Abel EA et al, in this study $5(35.7 \%)$ out of 14 patients had complete clearance of lesions after 15 to 40 treatments.[16]

3. Norbert J. Neumann et al, showed $64.64 \%$ reduction of PASI score.[17]

4. Tsankov $\mathrm{N}$ et al, this study showed $40 \%$ of patients had marked improvement after 15 sessions of PUVA therapy.[18]

5. Petty A et al, reported the most commonly used therapeutic options for palmoplantar psoriasis are longterm treatment with topical corticosteroids and handfoot PUVA, but the disease become resistant to these modalities after sometime.[19]

6. Tsankov $\mathrm{N}$ et al, showed no statistically significant difference between the combination of calcipotriol with UVA phototherapy and PUVA in regard to the therapeutic effect.[20]

In our study for the treatment of palmoplantar psoriasis with PUVA therapy, 4 out of 22 patients (18.18\%) had complete clearance of palmar psoriasis and 2 patients (9.09\%) had complete clearance of plantar psoriasis after 34 to 44 treatment sessions; $18 \%$ of patients developed adverse effect during treatment. In the followup period, 3 patients developed relapse after 15 weeks of remission. These findings in our study are comparable to the above mentioned studies conducted for the treatment of palmoplantar psoriasis with PUVA therapy.

The disadvantages of PUVA are unavailability of PUVA chamber in many centres, repeated hospital visits and longterm side effects.

\section{Combination of Calcipotriol with Clobetasol Propionate Ointment (Group B)}

The topical calcipotriol and clobetasol propionate ointment was given in a sequential manner for 6 months. In this group maximum percentage reduction of PASI score was $29.55 \%$, $50.56 \%$ and $70.77 \%$ at the end of $8^{\text {th }}, 16^{\text {th }}$ and $24^{\text {th }}$ weeks respectively. The maximum improvement was observed at the end of $16^{\text {th }}$ and $24^{\text {th }}$ weeks.

Studies related to the treatment of palmoplantar psoriasis with combination of topical calcipotriol and steroids were very less, but many studies were done with combination of calcipotriol and steroids for the treatment of other type of psoriasis.

These combinations showed better results for the treatment of localised plaque type of psoriasis. Even though the onset of action of calcipotriol is slow, steroid will trigger its action and reduces the irritant potential of calcipotriol. The advantage of calcipotriol is that it can be given safely for children, diabetics and hypertensive patients.

In a randomised, double-blinded, controlled trial of Van der Vleuten $\mathrm{CJ}$ et al,[21] 71.2\% of patients achieved "absent" or "very mild" disease with the two-compound scalp formulation, compared to $64 \%$ with betamethasone dipropionate and $36.8 \%$ with calcipotriene alone. But the disadvantage is pruritus in the combination. ${ }^{21,22]}$ 
The efficacy of occlusive topical calcipotriol therapy is better than non-occlusive therapy. The study by Duweb et al showed better efficacy with occlusive calcipotriol applied for 6 weeks; twice-weekly occlusive calcipotriol ointment was as effective as the twice-daily application. [23]

A study by Lebwohl $\mathrm{M}$ and Menter $\mathrm{A}$ et al, revealed that a high-potency topical corticosteroid in combination with vitamin D analog gave better efficacy, although it does not appear to be as effective as super potent corticosteroid used alone.[24,25] A combination with super potent topical clobetasol or halobetasol gave better results than with high potent topical betamethasone ointment.

In a similar study by Koo J, Blum RR and Lebwohl M (2006) et al with the combination of topical calcipotriol with clobetasol, there was a 92\% clearance of skin lesions after 6 months of therapy.

In our study, $66.7 \%$ of patients showed more than $70 \%$ clearance of psoriatic skin lesions after 6 months of therapy with topical calcipotriol and clobetasol with least side effects. Seven patients $(29.16 \%)$ showed $100 \%$ clearance of palmar psoriasis and five patients (20.83\%) showed $100 \%$ clearance of plantar psoriasis after six months of therapy, which is comparable with the study done by Koo J, Blum RR, Lebwohl $\mathrm{M}$ (2006) et al.

\section{CONCLUSION}

1. Efficacy of topical calcipotriol ointment and steroid used in sequential manner is better than the topical psoralen ultraviolet A therapy.

2. 22 patients $(91.6 \%)$ in calcipotriol and steroid combination group showed more than $50 \%$ reduction of PASI score. But in PUVA therapy group, $81.8 \%$ of patients showed more than $50 \%$ reduction of PASI score.

3. On comparing the adverse effects, patients on PUVA therapy group developed more adverse effects than the patients on calcipotriol and steroid combination group.

4. The duration of remission maintenance was long in calcipotriol and steroid combination group when compared to PUVA therapy group.

In our study, we arrived at the conclusion that topical therapies used in a sequential manner was more effective and it may be considered as a first line therapy for the treatment of patients with palmoplantar psoriasis.

\section{REFERENCES}

[1] Farber EM, Nall ML. The natural history of psoriasis in 5,600 patients. Dermatologica 1974;148(1):1-18.

[2] Carlin CS, Feldman SR, Krueger JG, et al. A 50\% reduction in the psoriasis area and severity index (PASI 50) is a clinically significant endpoint in the assessment of psoriasis. J Am Acad Dermatol 2004;50(6):859-66.

[3] Jacobson CC, Kimball AB. Rethinking the psoriasis area and severity index: the impact of area should be increased. Br J Dermatol 2004;151(2):381-7.

[4] De Kerkhof PCV, Kragballe K, Austad J, et al. Psoriasis: severity assessment in clinical practice. Conclusions from workshop discussions and a prospective multicentre survey of psoriasis severity. Eur J Dermatol 2006;16(2):167-71.
[5] Katz KA. Psoriasis area and severity index 50 as an endpoint in psoriasis trials: an unconvincing proposal. J Am Acad Dermatol 2005;53(3):547-51.

[6] Wahab MA, Amin MN, Khan MAL, et al. Bath PUVA in the treatment of palmoplantar psoriasis. J Bangladesh Coll Phys Surg 2006;24(1):14-8.

[7] Weinstein GD, White GM. An approach to the treatment of moderate to severe psoriasis with rotational therapy. J Am Acad Dermatol 1993;28(3):454-9.

[8] Koo J. Systemic sequential therapy for psoriasis: a new paradigm for improved therapeutic results. J Am Acad Dermatol 1999;41(3 Pt 2):S25-8.

[9] Zanolli M. Phototherapy arsenal in the treatment of psoriasis. Dermatol Clin 2004;22(4):397-406.

[10] Coven TR, Walters IB, Cardinale I, et al. PUVA-induced lymphocyte apoptosis: mechanism of action in psoriasis. Photodermatol Photoimmunol photomed 1999;15(1):22-7.

[11] Halpern SM, Anstey AV, Dawe RS, et al. Guidelines for topical PUVA: a report of a workshop of the British photodermatology group. $\mathrm{Br} \quad \mathrm{J}$ Dermatol 2000;142(1):22-31.

[12] Yosipovitch G, Tang MB. Practical management of psoriasis in the elderly: epidemiology, clinical aspects, quality of life, patient education and treatment options. Drugs Aging 2002;19(11):847-63.

[13] Gonzalez E. PUVA for psoriasis. Dermatologic clinics. In: Lebwokl M, Zanolli M, (eds). Vol:13, No-4, Saunders 1999:851-66.

[14] Boyvat A, Erdi H, Birol A, et al. Interaction of commonly used emollients with photochemotherapy. Photodermatol Photoimmunol Photomed 2000;16(4):156-160.

[15] Wilkinson JD, Ralfs IG, Harper JI, et al. Topical methoxsalen photochemotherapy in the treatment of palmoplantar pustulosis and psoriasis. Acta Derm Venereol Suppl (Stockh) 1979;59(85):193-8.

[16] Abel EA, Goldberg LH, Farber EM. Treatment of palmoplantar psoriasis with topical methoxsalen plus long-wave ultraviolet light. Arch Dermatol 1980;116(11):1257-61.

[17] Neumann NJ, Mahnke N, Korpusik D, et al. Treatment of palmoplantar psoriasis with monochromatic excimer light (308-nm) versus cream PUVA. Acta Derm Venereol 2006;86(1):22-4.

[18] Tsankov N, Meymandi S, Grozdev I, et al. Palmoplantar psoriasis: treatment with calcipotriol and local UVA radiation compared with local PUVA. J Laser Med Sci 2011;2(1):1-5.

[19] Pettey AA, Balkrishnan R, Rapp S, et al. Patients with palmoplantar psoriasis have more physical disability and discomfort than patients with other forms of psoriasis: implications for clinical practice. J Am Acad Dermatol 2003;49(2):271-5.

[20] Vleuten CJVD, Kerkhof PCVD. Management of scalp psoriasis: guidelines for corticosteroid use in combination treatment. Drugs 2001;61(11):1593-8. 
[21] Jemec GB, Ganslandt C, Ortonne JP, et al. A new scalp formulation of calcipotriene plus betamethasone compared with its active ingredients and the vehicle in the treatment of scalp psoriasis: a randomized, double-blind, controlled trial. J Am Acad Dermatol 2008;59(3):455-63.

[22] Duweb GA, Abuzariba 0, Rahim M, et al. Occlusive versus nonocclusive calcipotriol ointment treatment for palmoplantar psoriasis. Int $\mathrm{J}$ Tissue React 2001;23(2):59-62.

[23] Lebwohl M, Siskin SB, Epinette W, et al. A multicenter trial of calcipotriene ointment and halobetasol ointment compared with either agent alone for the treatment of psoriasis. J Am Acad Dermatol 1996;35(2 Pt 1):268-9.
[24] Menter A, Abramovits W, Colon LE, et al. Comparing clobetasol propionate $0.05 \%$ spray to calcipotriene $0.005 \%$ betamethasone dipropionate $0.064 \%$ ointment for the treatment of moderate to severe plaque psoriasis. J Drugs Dermatol 2009;8(1):52-7.

[25] Koo J, Blum RR, Lebwohl M. A randomized, multicenter study of calcipotriene ointment and clobetasol propionate foam in the sequential treatment of localized plaque psoriasis: short-and long-term outcomes. J Am Acad Dermatol 2006;55(4):637-41. 